\title{
Hyponatremia is associated with poor outcome in COVID-19
}

\author{
Hugo De Carvalho ${ }^{1}$ - Thibault Letellier ${ }^{2} \cdot$ Matilde Karakachoff $^{3} \cdot$ Geoffrey Desvaux $^{4} \cdot$ Hélène Caillon $^{5}$. \\ Emmanuelle Papuchon ${ }^{2} \cdot$ Maxime Bentoumi-Loaec $^{2} \cdot$ Nesrine Benaouicha $^{1} \cdot$ Emmanuel Canet $^{6}$. \\ Guillaume Chapelet $^{7} \cdot$ Paul Le Turnier $^{8} \cdot$ Emmanuel Montassier $^{1} \cdot$ Armine Rouhani $^{9} \cdot$ Nicolas Goffinet $^{1}$. \\ Lucile Figueres ${ }^{2,10}$
}

Received: 7 November 2020 / Accepted: 3 February 2021 / Published online: 7 April 2021

(C) Italian Society of Nephrology 2021

\begin{abstract}
Aim Our objective was to describe the impact of hyponatremia on the outcomes of COVID-19 patients [outcomes selected: intensive care unit (ICU) admission, mechanical ventilation or death].

Methods Two groups of COVID-19 patients were retrospectively screened on the basis of plasma sodium level at admission: hyponatremic (sodium $<135 \mathrm{mM}, \mathrm{n}=92$ ) or normonatremic (sodium $\geq 135 \mathrm{mM}, \mathrm{n}=198$ ) patients. Pearson's chi- ${ }^{2}$ (qualitative variables) and Student's $T$ tests (quantitative variables) were used to compare the two groups. A multiple logistic regression model was used to explore the association between patients' clinical data and outcomes.

Results Hyponatremia was frequent but generally mild. There were more male patients in the hyponatremic group $(\mathrm{p}=0.014)$. Pulmonary lesions on the first thoracic CT-scan performed during hospitalization were significantly more extensive in the hyponatremic group $(\mathrm{p}=0.010)$. ICU admission, mechanical ventilation or death were significantly more frequent in hyponatremic compared to normonatremic patients (37 versus $14 \% ; p<0.001 ; 17$ versus $6 \% ; p=0.003 ; 18$ versus $9 \%, p=0.042$, respectively). Hyponatremia was an independent predictor of adverse outcomes (adjusted Odds-ratio: 2.77 [1.26-6.15, $\mathrm{p}=0.011]$ ).

Conclusions Our study showed an independent relationship between hyponatremia at admission and transfer to ICU, use of mechanical ventilation or death in COVID-19 patients. Hyponatremia may reflect the severity of underlying pulmonary lesions. Our results support the use of sodium levels as a simple bedside screening tool for the early identification of SARS$\mathrm{CoV}-2$ infected patients at high risk of poor outcome.
\end{abstract}

Keywords COVID-19 $\cdot$ Hyponatremia $\cdot$ SIAD

Lucile Figueres

lucile.figueres@chu-nantes.fr

1 Emergency Department, Nantes University Hospital, Nantes, France

2 Nephrology Department, Nantes University Hospital, Nantes, France

3 Clinique des données, CIC-EC, Nantes University Hospital, Nantes, France

4 IT Department, Nantes University Hospital, Nantes, France

5 Biochemistry Department, Nantes University Hospital, Nantes, France
6 Medical Intensive Care Unit, Nantes University Hospital, Nantes, France

7 Geriatric Department, Nantes University Hospital, Nantes, France

8 Infectious Disease Department, Nantes University Hospital, Nantes, France

9 Anesthesiology and Intensive Care Department, Nantes University Hospital, Nantes, France

10 Service de Néphrologie et d'immunologie Clinique, CHU de Nantes, Place Alexis Ricordeau, 44100 Nantes, France 


\section{Background}

As the SARS-CoV-2 infection spreads worldwide, the search for prognostic factors is essential in order to provide adapted care and improve patient survival. Obesity, age, gender or acute kidney failure have been reported as prognostic factors [1-3], such as lymphocyte count [4], C-Reactive protein [5], troponin [6], D-dimer [7], or high serum concentrations of IL-6 [8].

Hyponatremia, has previously been described as an independent predictive factor of poor outcome in critically ill patients [9], as is the case in severe acute respiratory syndrome (SARS). This condition occurred in one third of the SARS-CoV-1 infected patients and was associated with poor prognosis $[10,11]$. Recent studies demonstrated that hyponatremia was associated with poor outcome in COVID-19 but these studies did not include European patients $[12,13]$ and/or did not consider plasma sodium levels at admission [13]. Also, genetic background is a risk factor for respiratory failure in COVID-19 [14], and as a consequence, prognostic factors may differ among populations. To date, the outcome of hyponatremia in European COVID-19 patients has not been extensively described.

Our objective was to describe the impact of hyponatremia on the outcome of COVID-19 patients [considering as outcomes: intensive care unit (ICU) admission, use of mechanical ventilation or death].

\section{Methods}

We carried out a retrospective study on 296 adult patients admitted to Nantes hospital from February 1st to May 7th, 2020 with a final diagnosis of COVID-19, confirmed by positive reverse transcription-PCR (RT-PCR) of a nasopharyngeal swab. Age below 18 years, hypernatremia and previous hospitalization for COVID-19 were exclusion criteria. Plasma sodium concentration was measured within $24 \mathrm{~h}$ of COVID-19 suspicion (assessed by the nasopharyngeal RT-PCR). Hyponatremia was defined as a sodium level below $135 \mathrm{mM}$. Epidemiological, demographic, clinical, laboratory and outcome data were extracted from electronic health records using a standard data collection form. Extracted data included demographic data, time between symptom onset and hospital admission, and known comorbidities (diabetes, congestive heart failure, coronary artery disease, cirrhosis, active neoplasia, current smoker, lung disease and obesity defined as a body mass index $\geq 30 \mathrm{~kg} / \mathrm{m}^{2}$ ). Vital parameters (tympanic temperature, systolic and diastolic blood pressure, respiratory rate, oxygen flow rate) and biological data [serum creatinine, lymphocyte count, fibrinogen, Alanine transaminase (ALT), Aspartate transaminase (AST), Troponin T hs, Creatine Kinase, C-Reactive protein] collected during the first $24 \mathrm{~h}$ were gathered. Oxygen saturation $\left(\mathrm{SpO}_{2}\right)$ was not considered as it was often recorded after the start of oxygen therapy. Subjective symptoms were retrospectively analyzed with a significant number of missing values. Data concerning the first CT-scan performed during hospitalization, focusing on the extent of COVID-19 lesions were also extracted. Patients underwent CT-scan to assess the severity of COVID-19 or to look for an associated diagnosis (i.e. pulmonary embolism or bacterial pneumonia). Previous plasma sodium concentrations evaluated at the same laboratory during the twelve months preceding COVID-19 diagnosis were retrospectively extracted, whenever possible, for hyponatremic patients. The primary outcome for our study was to assess whether hyponatremia is associated with poor outcome, as defined by ICU admission, use of mechanical ventilation or death.

Patients were admitted to the ICU due to acute respiratory failure (respiratory rate $>20 / \mathrm{min}$ ), hypoxemia $\left(\mathrm{SpO}_{2}<92 \%\right.$ with oxygen therapy above $\left.6 \mathrm{~L} / \mathrm{min}\right)$, coma $(\mathrm{GCS}<12)$ or hemodynamic instability (systolic blood pressure $<90 \mathrm{mmHg}$ ).

Results are expressed as proportions with $95 \%$ confidence intervals, mean with standard deviation or median with 25 th-75th percentile. Pearson's chi ${ }^{2}$ test (or Fisher's Exact test) was used for qualitative variables and Student's $t$ test (or Wilcoxon test) for quantitative variables to compare the two groups (hyponatremic and normonatremic patients). $\mathrm{Chi}^{-}{ }^{2}>3.84$ and $p$ value $<0.05$ were considered statistically significant. After withdrawing variables with more than $20 \%$ of missing values (subjective symptoms, obesity, CTscan, Creatine Kinase, C-Reactive Protein, Troponin T hs, fibrinogen, D-dimer), a multiple logistic regression model was used to assess the association of outcome and patient data. Kaplan-Meier survival curves were used to visually represent the results. The log-rank test was used to compare survival between hyponatremic and normonatremic patients. Variables included in the model were selected if $p$ value was $<0.2$ in the univariate logistic regression model, except for serum creatinine and lymphocyte count, which were forced in the model, as already described as independent prognostic factors $[2,4]$. The local ethics committee approved the study (GNEDS April 23rd, 2020).

\section{Results}

\section{Baseline data}

Two groups of patients were identified on the basis of plasma sodium levels at admission: hyponatremic 
(sodium $<135 \mathrm{mM}, \mathrm{n}=92,31 \%$ of the cohort) and normonatremic (sodium $\geq 135 \mathrm{mM}, \mathrm{n}=198$ ) patients. Six patients with hypernatremia (sodium $>145 \mathrm{mM}$ ) were excluded. Risks of ICU admission, mechanical ventilation or death, were significantly higher in hyponatremic compared to normonatremic patients (respectively, $37 \%$ versus $14 \% ; \mathrm{p}<0.001 ; 17 \%$ versus $6 \% ; \mathrm{p}=0.003 ; 18 \%$ versus $9 \%$, $\mathrm{p}=0.042$ ) (Table 1). Risk of all adverse outcomes was significantly higher in hyponatremic patients compared to normonatremic patients $(41 \%$ versus $20 \%, \mathrm{p}<0.001)$ (Table 1 and Fig. 1).

Age and time between symptom onset and hospital admission were similar between hyponatremic and normonatremic patients (Table 1 ). There were significantly more male patients in the hyponatremic group $(p=0.014)$. The prevalence of major comorbidities typically associated with hyponatremia (cirrhosis, active neoplasia), and obesity did not differ between groups.

\section{Prognostic factors}

We looked for prognostic factors in our cohort. Body temperature at admission was significantly higher in hyponatremic patients $(\mathrm{p}<0.001)$. Fifty-five out of $85(65 \%)$ patients and 80 out of 171 (47\%) had a temperature above $38.5{ }^{\circ} \mathrm{C}$ in hyponatremic and normonatremic patients, respectively (Pearson $\mathrm{Chi}^{-}{ }^{2}$ test $\mathrm{p}=0.010$ ), which indicates a significant correlation between high fever and hyponatremia. At admission, serum creatinine and lymphocyte counts were similar in the two groups (Table 2). C-Reactive protein was significantly higher in hyponatremic patients $(p=0.040)$, even if with a non-negligible number of missing values (32\% in the hyponatremic versus $22 \%$ in the normonatremic group) (Table 2). AST and ALT were also significantly higher in hyponatremic patients (respectively, p < 0.001 and 0.009) (Table 2).

\section{Multiple regression analysis}

We performed a multivariate analysis entering the following variables of interest (known as prognostic factor and/or with a $p$ value $<0.2$ in univariate analysis, after withdrawing variables with more than $20 \%$ of missing values): age, sex, tympanic temperature, diabetes, serum creatinine, ALT, lymphocyte count and oxygen flow rate at admission (Table 3). Due to a significant correlation with ALT, and to the presence of more missing values, AST was not included in the model. Respiratory rate and oxygen flow rate (divided into three categories [none, $\leq 6 \mathrm{l} / \mathrm{min},>6 \mathrm{l} / \mathrm{min}$ ]) were also strongly associated with outcomes (Kruskal Wallis test, $\mathrm{p}=1.9 \mathrm{e}-07$ ). However, respiratory rate information was not available for 60 patients ( $21 \%$ of the cohort). Thus, this parameter was not included in the final model. In the multivariate analysis, hyponatremia at admission was an independent predictor of poor outcome (adjusted odds-ratio: 2.77 [1.26-6.15, $\mathrm{p}=0.011])$ together with an oxygen flow rate above $6 \mathrm{l} /$ min (adjusted odds-ratio: 16.90 [5.56-58.97, p<0.001]) (Table 3). Tympanic temperature, which was significantly higher in the hyponatremic group, was also an independent predictor of poor outcome in our cohort (adjusted odds-ratio: 2.67 [1.13-6.69, $\mathrm{p}=0.029]$ (Table 3).

\section{Characteristics of hyponatremia}

Hyponatremia was generally mild (mean plasma sodium level in the hyponatremic group $132.1 \pm 1.9 \mathrm{mM} / 1$ [125-134]). Only 9 patients had a sodium level below $130 \mathrm{mM}$. Thirty out of 92 hyponatremic patients (33\%) had undergone plasma sodium measurement in the same laboratory during the year preceding COVID-19 and 10 were found to have been previously hyponatremic.

Plasma osmolality was rarely measured in our non-interventional retrospective cohort of mild hyponatremia (12 patients), and when it was measured, it was mostly after intravenous fluid administration. Thus, we unfortunately did not have consistent plasma osmolality data. Of note, only 3 out of 12 samples were below $280-\mathrm{mOsm} / \mathrm{kg} / \mathrm{H}_{2} \mathrm{O}$. Of 34 urinary sodium measurements at admission in the hyponatremic patients, 15 (44\%) had $<30 \mathrm{mM}$ natriuresis, which may suggest an extracellular dehydration state. Systolic blood pressure at admission and digestive symptoms (diarrhea, vomiting) did not significantly differ between the hyponatremic and normonatremic groups (Table 1). Neurologic symptoms (headache, confusion) previously described in COVID-19 [15, 16] were also not significantly different between groups at admission (Table 1).

\section{Hyponatremia and severity of pulmonary lesions}

Oxygen flow at admission did not differ between hyponatremic and normonatremic patients (Table 1). Mean oxygen flow rate in patients with oxygen flow rate $\leq 61 / \mathrm{min}$ was not significantly different (Table 1). Comparison between the pulmonary lesions of hyponatremic and normonatremic patients is reported in Table 2 .

One hundred twenty-three patients in our cohort underwent pulmonary assessment by CT-scan. Pulmonary lesions on the first thoracic CT-scan performed during hospitalization were significantly more extensive in the hyponatremic compared to the normonatremic group (Pearson $\mathrm{Chi}^{2}{ }^{2}$ test, $\mathrm{p}=0.010$ ) (Table 2), and extension of the lesions to more than $50 \%$ of the lungs was associated with poor outcome in univariate analysis (odds-ratio 17.25 [5.64-61.06, $\mathrm{p}<0.001]$ ) (Table 3). 
Table 1 Characteristics and outcomes of the two groups of patients (hyponatremic or normonatremic at admission)

\begin{tabular}{|c|c|c|c|c|c|}
\hline & $\begin{array}{l}\text { Missing values } \\
\mathrm{N}(\%)\end{array}$ & Hyponatremic $(\mathrm{n}=92)$ & $\begin{array}{l}\text { Missing val- } \\
\text { ues, N (\%) }\end{array}$ & $\begin{array}{l}\text { Normonatremic } \\
(\mathrm{n}=198)\end{array}$ & $\mathrm{p}$ \\
\hline Age $-\mathrm{y} \pm \mathrm{SD}$ & 0 & $67 \pm 16$ & 0 & $69 \pm 18$ & 0.517 \\
\hline Male (n/\%) & 0 & $61(66)$ & 0 & $98(50)$ & 0.014 \\
\hline $\begin{array}{l}\text { Time between symptom onset and admission- } \\
\text { days* } \pm \text { IQR }\end{array}$ & 0 & $6[3-9]$ & 0 & $5[1-9]$ & 0.152 \\
\hline \multicolumn{6}{|l|}{ Comorbidities } \\
\hline Diabetes (n/\%) & 0 & $18(19)$ & 0 & $31(16)$ & 0.536 \\
\hline Obesity (n/\%) & $18(20)$ & $20 / 80(27)$ & $58(29)$ & $58(29)$ & 0.390 \\
\hline Congestive heart failure (n/\%) & 0 & $5(5)$ & 0 & $25(13)$ & 0.064 \\
\hline Coronary artery disease $(\mathrm{n} / \%)$ & 0 & $14(15)$ & 0 & $30(15)$ & 1.000 \\
\hline Cirrhosis (n/\%) & 0 & $1(1)$ & 0 & $2(1)$ & 1.000 \\
\hline Active neoplasia (n/\%) & 0 & $6(7)$ & 0 & $12(6)$ & 1.000 \\
\hline Current smoker (n/\%) & 0 & $9(10)$ & 0 & $13(7)$ & 0.485 \\
\hline Chronic obstructive pulmonary disease (n/\%) & 0 & $11(12)$ & 0 & $16(8)$ & 0.386 \\
\hline History of pulmonary neoplasia (n/\%) & 0 & $2(2)$ & 0 & $3(2)$ & 0.656 \\
\hline Respiratory insufficiency (n/\%) & 0 & $1(1)$ & 0 & $1(1)$ & 0.538 \\
\hline \multicolumn{6}{|l|}{ Usual medications } \\
\hline $\operatorname{ACEi}(\mathrm{n} / \%)$ & 0 & $13(14)$ & 0 & $17(9)$ & 0.214 \\
\hline $\mathrm{ARB}(\mathrm{n} / \%)$ & 0 & $8(9)$ & 0 & $20(10)$ & 0.832 \\
\hline Loop diuretics $(\mathrm{n} / \%)$ & 0 & $9(10)$ & 0 & $8(4)$ & 0.065 \\
\hline Thiazides (n/\%) & 0 & $3(3)$ & 0 & $20(10)$ & 0.060 \\
\hline \multicolumn{6}{|l|}{ Vital signs } \\
\hline Body temperature $\left({ }^{\circ} \mathrm{C}\right)$ & $8(9)$ & $38.9 \pm 0.9$ & $27(14)$ & $38.4 \pm 0.9$ & $<0.001$ \\
\hline Temperature $>38.5$ & & $55(65)$ & & $80(47)$ & 0.010 \\
\hline Systolic blood pressure (mmHg) & $5(5)$ & $148 \pm 18$ & $8(4)$ & $149 \pm 22$ & 0.709 \\
\hline Diastolic blood pressure (mmHg) & $5(5)$ & $83 \pm 9$ & $8(4)$ & $86 \pm 12$ & 0.110 \\
\hline Respiratory rate (/min) & $13(14)$ & $30 \pm 7$ & $47(24)$ & $28 \pm 7$ & 0.034 \\
\hline \multicolumn{6}{|l|}{ Symptoms } \\
\hline Diarrhea (n/\%) & $2(2)$ & $29(32)$ & $4(2)$ & $62(32)$ & 1.000 \\
\hline Vomiting (n/\%) & $2(2)$ & $10(11)$ & $4(2)$ & $16(8)$ & 0.597 \\
\hline Agueusia (n/total n, \%) & $26(28)$ & $21 / 74(31)$ & $70(35)$ & $32 / 148(25)$ & 0.438 \\
\hline Anosmia (n/total n, \%) & $26(28)$ & $19 / 74(28)$ & $72(36)$ & $26 / 146(21)$ & 0.303 \\
\hline Neurological involvement (n/\%) & $1(1)$ & $16(17)$ & $7(4)$ & $24(13)$ & 0.363 \\
\hline \multicolumn{6}{|l|}{ Oxygen therapy } \\
\hline Oxygen therapy & $3(3)$ & & $8(4)$ & & \\
\hline No oxygen therapy (n/total n, \%) & & $49(54)$ & & $118(62)$ & 0.298 \\
\hline Oxygen therapy $\leq 61 / \min (\mathrm{n} /$ total $\mathrm{n}, \%)$ & & $28(31)$ & & $55(29)$ & \\
\hline Mean oxygen flow- $-1 / \min \pm S D$ & & $3.5 \pm 1.5^{\mathfrak{f}}$ & & $3.0 \pm 1.3^{\mathfrak{f}}$ & \\
\hline Oxygen therapy $>61 / \min (\mathrm{n} /$ total $\mathrm{n}, \%)$ & & $13(14)$ & & $17(9)$ & \\
\hline \multicolumn{6}{|l|}{ Outcome } \\
\hline Total Poor outcome & 0 & $38(41)$ & 0 & $40(20)$ & $<0.001$ \\
\hline Transfer to ICU (n/\%) & 0 & $34(37)$ & 0 & $27(14)$ & $<0.001$ \\
\hline Mechanical ventilation (n/\%) & 0 & $16(17)$ & 0 & $11(6)$ & 0.003 \\
\hline Death $(\mathrm{n} / \%)$ & 0 & $17(18)$ & 0 & $18(9)$ & 0.042 \\
\hline
\end{tabular}

Main clinical symptoms and comorbidities of the patients are reported. Body mass index was not available for all patients, such as subjective symptoms (missing values are indicated). Oxygen flow rate was classified into three groups (no oxygen therapy, $\leq 61 / \mathrm{min},>61 / \mathrm{min}$ )

Results are expressed as mean \pm standard deviation (SD) or median [Inter Quartile Range] for quantitative variables, and comparability between groups was evaluated by Student's t or non-parametric Wilcoxon test $\left(^{*}\right)$. P value is indicated for each test $(\mathrm{p}<0.05$ was considered significant)

Results are expressed with number of patients/percentage for qualitative variables, and comparability between groups was evaluated by Pearson's $\mathrm{Chi}^{2}$ test with chi- $^{2}>3.84$ considered significant

${ }^{£}$ Not significant $(\mathrm{p}=0.08)$ 
Fig. 1 Overall survival estimate without poor-outcome since hospital admission in hyponatremic and normonatremic patients

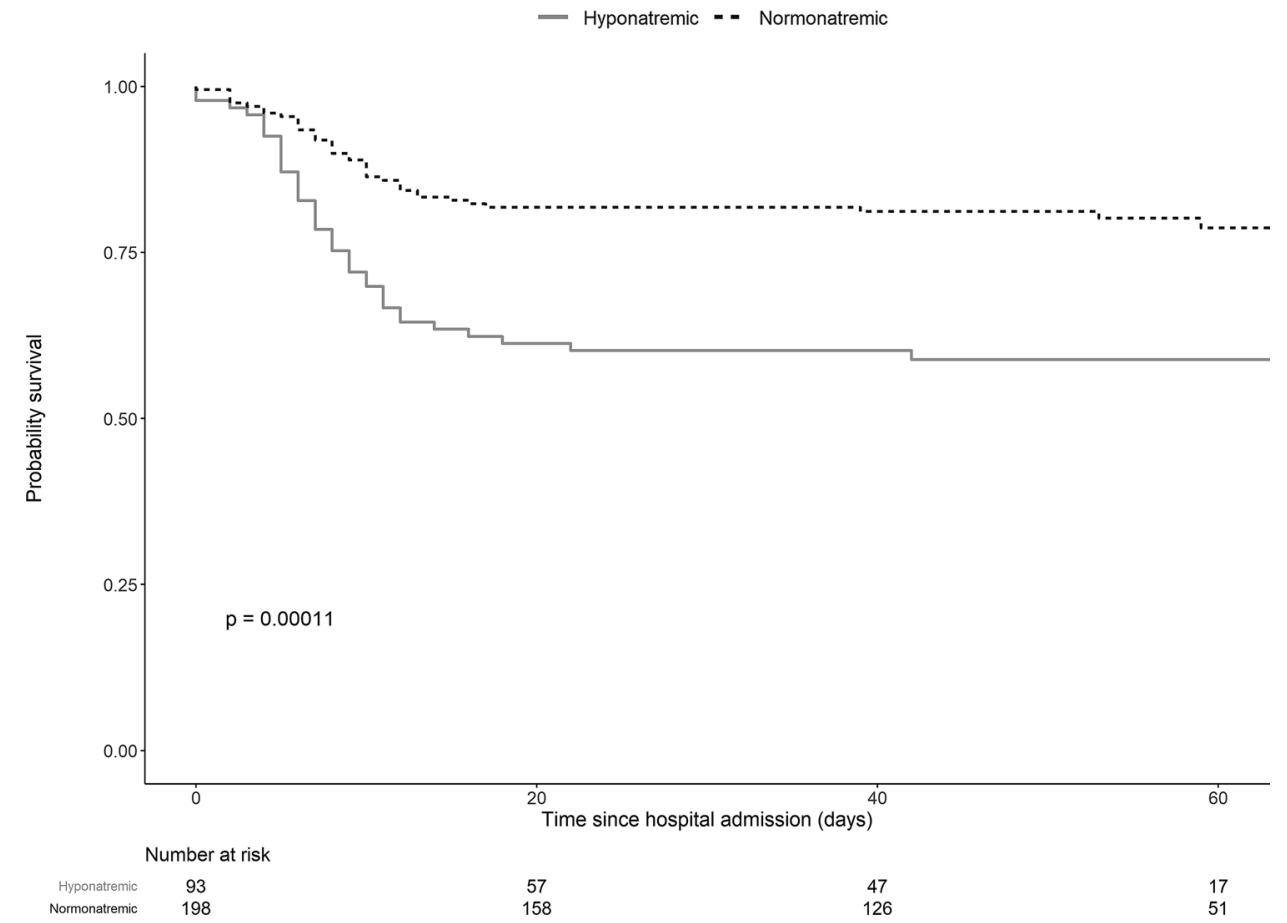

Table 2 Biological parameters at admission and CT-scan reports in the two groups of patients (hyponatremic or normonatremic)

\begin{tabular}{|c|c|c|c|c|c|}
\hline & $\begin{array}{l}\text { Missing val- } \\
\text { ues, N (\%) }\end{array}$ & Hyponatremic $(\mathrm{n}=92)$ & $\begin{array}{l}\text { Missing val- } \\
\text { ues N (\%) }\end{array}$ & Normonatremic $(\mathrm{n}=198)$ & $\mathrm{p}$ \\
\hline \multicolumn{6}{|l|}{ Biological parameters } \\
\hline Creatinine $(\mu \mathrm{M})$ & $0(0)$ & $89 \pm 39$ & $1(0.5)$ & $92 \pm 47$ & 0.7121 \\
\hline Lymphocyte counts* $\left(\times 10^{9} / 1\right)$ & $2(2)$ & $0.87[0.61-1.18]$ & $11(6)$ & $0.96[0.71-1.454]$ & 0.108 \\
\hline $\mathrm{ALT}^{*}(\mathrm{UI} / \mathrm{l})$ & $21(23)$ & 38 [25-72] & $33(17)$ & $30[20-45]$ & 0.009 \\
\hline $\operatorname{AST}^{*}(\mathrm{UI} / \mathrm{l})$ & $21(23)$ & $54[42-83]$ & $35(18)$ & 38 [27-55] & $<0.001$ \\
\hline Fibrinogen* $(\mathrm{g} / \mathrm{l})$ & $49(53)$ & $5.0[4.2-7.4]$ & $96(48)$ & $4.6[4.1-6.4]$ & 0.093 \\
\hline C-Reactive protein* (mg/l) & $30(32)$ & $66[31-130]$ & $43(22)$ & $40[11-85]$ & 0.040 \\
\hline Troponin* (ng/l) & $32(34)$ & $13[8-28]$ & $84(42)$ & $17[9-35]$ & 0.186 \\
\hline Creatine Kinase* (UI/l) & $40(43)$ & $124[63-302]$ & $89(45)$ & $96[55-223]$ & 0.344 \\
\hline D-dimer* (ng/ml) & $67(72)$ & 716 [454-1244] & $142(72)$ & 608 [377-988] & 0.236 \\
\hline \multicolumn{6}{|l|}{ CT-scan } \\
\hline Thoracic CT-scan performed (n/\%) & & $48(52)$ & & $75(38)$ & \\
\hline CT-scan $<30 \%$ lesions (n/total n, \%) & & $9(19)$ & & $33(44)$ & 0.010 \\
\hline CT-scan: $30-50 \%$ lesions (n/total n, \%) & & $22(46)$ & & $28(37)$ & \\
\hline CT-scan: $>50 \%$ lesions (n/total n, \%) & & $17(35)$ & & $14(19)$ & \\
\hline
\end{tabular}

Main biological parameters at admission including known prognostic markers and extension of SARS CoV-2 lesions on CT-scans are reported. Extension of lesions was classified into three groups $(<30 \%, 30-50 \%,>50 \%)$. Missing values are indicated

Results are expressed as mean \pm standard deviation (SD) or median [Inter Quartile Range] for quantitative variables, and comparability between groups was evaluated by Student's T or non parametric Wilcoxon test $\left(^{*}\right)$. $\mathrm{p}$ value is indicated for each test $(\mathrm{p}<0.05$ was considered significant)

Results are expressed with number of patients/percentage for qualitative variables, and comparability between groups was evaluated by Pearson's $\mathrm{Chi}^{2}$ test with chi- $^{2}>3.84$ considered significant

\section{Discussion}

Several prognostic factors have been reported in
COVID-19. Although hyponatremia is common in larger cohorts of COVID-19 [18], its prognostic value has only been studied recently in American [12], Chinese [13] and Turkish [19] patients, and results showed that 
Table 3 Univariable and multivariable Logistic Regression for poor outcome

\begin{tabular}{|c|c|c|c|}
\hline & $\begin{array}{l}\text { Missing } \\
\text { values }(\%)\end{array}$ & OR (univariable) & OR (multivariable) \\
\hline Hyponatremia & 0 & $2.73(1.59-4.70, \mathrm{p}<0.001)$ & $2.77(1.26-6.15, p=0.011)$ \\
\hline Age & 0 & $0.99(0.97-1.00, \mathrm{p}=0.145)$ & $1.01(0.99-1.04, \mathrm{p}=0.356)$ \\
\hline Male & 0 & $1.70(1.00-2.94, \mathrm{p}=0.051)$ & $1.18(0.53-2.69, \mathrm{p}=0.687)$ \\
\hline Diabetes & 0 & $1.41(0.71-2.70, \mathrm{p}=0.312)$ & $1.74(0.67-4.41, \mathrm{p}=0.244)$ \\
\hline Temperature & 12 & $2.55(1.79-3.76, \mathrm{p}<0.001)$ & N/A \\
\hline Temperature $>38.5^{\circ} \mathrm{C}$ & & $3.39(1.83-6.56, \mathrm{p}<0.001)$ & $2.67(1.13-6.69, p=0.029)$ \\
\hline \multicolumn{4}{|l|}{ Oxygen therapy } \\
\hline None & 4 & & \\
\hline$\leq 61 / \mathrm{min}$ & & $1.68(0.88-3.18, \mathrm{p}=0.112)$ & $1.54(0.67-3.54, p=0.309)$ \\
\hline$>61 / \mathrm{min}$ & & $19.86(7.87-57.76, \mathrm{p}<0.001)$ & $16.90(5.56-58.97, p<0.001)$ \\
\hline Creatinine* & 0.3 & $1.00(1.00-1.01, \mathrm{p}=0.312)$ & $0.96(0.34-2.60, \mathrm{p}=0.939)$ \\
\hline $\mathrm{ALT}^{*}$ & 19 & $1.01(1.00-1.01, \mathrm{p}=0.036)$ & $1.54(0.67-3.54, \mathrm{p}=0.309)$ \\
\hline Lymphocyte count* & 13 & $1.05(0.98-1.14, \mathrm{p}=0.208)$ & $1.51(0.90-2.58, \mathrm{p}=0.121)$ \\
\hline $\begin{array}{l}\text { Time between onset of } \\
\text { symptoms and admission }\end{array}$ & 0 & $1.00(0.95-1.05, \mathrm{p}=0.944)$ & \\
\hline Obesity & 26 & $2.17(1.08-4.32, \mathrm{p}=0.028)$ & \\
\hline Congestive heart failure & 0 & $0.81(0.31-1.89, \mathrm{p}=0.651)$ & \\
\hline Coronary artery disease & 0 & $0.77(0.35-1.60, p=0.508)$ & \\
\hline Cirrhosis & 0 & $1.37(0.06-14.50, p=0.798)$ & \\
\hline Active neoplasia & 0 & $0.77(0.21-2.22, \mathrm{p}=0.651)$ & \\
\hline Current smoker & 0 & $1.62(0.63-3.96, p=0.296)$ & \\
\hline Diarrhea & 2.1 & $1.06(0.59-1.86, \mathrm{p}=0.841)$ & \\
\hline Vomiting & 2.1 & $1.33(0.52-3.10, \mathrm{p}=0.529)$ & \\
\hline Agueusia & 33.0 & $0.42(0.15-1.01, \mathrm{p}=0.070)$ & \\
\hline Anosmia & 33.7 & $0.54(0.19-1.30, \mathrm{p}=0.195)$ & \\
\hline Systolic blood pressure & 4.1 & $1.01(0.99-1.02, \mathrm{p}=0.258)$ & \\
\hline Diastolic blood pressure & 4.5 & $1.01(0.98-1.03, \mathrm{p}=0.519)$ & \\
\hline Respiratory rate & 21 & $1.12(1.07-1.18, \mathrm{p}<0.001)$ & \\
\hline Neurological involvement & 2.8 & $1.64(0.79-3.31, \mathrm{p}=0.172)$ & \\
\hline CT-scan & 57.7 & & \\
\hline$<30 \%$ lesions & & & \\
\hline $30-50 \%$ lesions & & $1.89(0.66-5.94, p=0.246)$ & \\
\hline$>50 \%$ lesions & & $17.25(5.64-61.06, \mathrm{p}<0.001)$ & \\
\hline AST & 19.2 & $1.01(1.00-1.01, \mathrm{p}=0.023)$ & \\
\hline Fibrinogen & 49.8 & $1.39(1.13-1.72, \mathrm{p}=0.002)$ & \\
\hline Troponin & 39.9 & $1.00(1.00-1.01, \mathrm{p}=0.222)$ & \\
\hline Creatine Kinase & 44.3 & $1.00(1.00-1.00, \mathrm{p}=0.660)$ & \\
\hline C-Reactive Protein & 25.1 & $1.01(1.01-1.02, \mathrm{p}<0.001)$ & \\
\hline
\end{tabular}

Odds-Ratios (OR) were calculated by univariable and multivariable not weighted logistic regression models. Subjective symptoms and variables with an excess of missing values (i.e. $>20 \%$ ) were withdrawn from the multivariable analysis. Due to the strong correlation with oxygen flow rate and the number of missing values, respiratory rate was not included in the multivariate analysis

N/A not applicable

*Creatinine, lymphocyte count and ALT were included in the model as natural logarithmic transformation hyponatremia was associated with poor outcome. However, data may be modulated by genetic background, and, to our knowledge, there are currently no available data regarding a European cohort. Mild hyponatremia, occurring in one third of our cohort of 290 COVID-19 hospitalized patients, was more frequent in males and appeared to be associated with poor outcomes (ICU admission, mechanical ventilation or death). Our results are in line with the previous finding in SARS COV 1 infection [10], in European COVID-19 patients. 
The physiopathology of hyponatremia in COVID-19 needs to be assessed.

In our cohort, we tried to evaluate whether patients were suffering from acute or chronic hyponatremia. Only two thirds of our hyponatremic patients for whom sodium values had been obtained in the twelve months prior to becoming infected with COVID-19 (30/92 patients) were previously normonatremic (10/30 patients with anteriority of hyponatremia). Underlying chronic hyponatremia may induce susceptibility for poor outcome in COVID-19, but our data suggest a role of acute hyponatremia in COVID-19. Hyponatremia may reflect a state of extracellular dehydration, as suggested by the low natriuresis found in almost half of the available urinary sodium measurements. Syndrome of inappropriate antidiuresis (SIAD) caused by lung parenchyma involvement may also be hypothesized. As SIAD has been associated with bacterial pneumonia and SARS, it must be determined whether hyponatremia reflects the severity of underlying pulmonary lesions. This is consistent with the more severe lesions on CT-scans in hyponatremic patients. Interestingly, the association between hyponatremia and poor outcomes was maintained after correction for oxygen flow rate at admission in the multivariate analysis.

Our retrospective study could not include all the prognostic factors which emerged from worldwide studies. Moreover, despite the significant number of patients involved in previously published cohorts, plasma sodium level was rarely considered as a prognostic factor. The reason may be that, by contrast to the other biological prognostic factors (i.e lymphocytes count, C-Reactive Protein, D-Dimer...), natremia is a regulated variable. In consequence, the status of the patient "hyponatremic versus normonatremic" is more reliable than considering natremia as a quantitative value. The disruption of this regulation is associated with the poor outcome in COVID-19. Temperature above $38.5^{\circ} \mathrm{C}$ at admission was also associated with poor outcome in our cohort, as already described as a prognostic factor in COVID-19 [20, 21]; interestingly hyponatremia may be associated with fever. We found a significant association between these two variables, both of which were associated with poor outcome in the multivariate analysis. Hyponatremia may be the result of a high concentration of interleukin-6 (IL-6), one of the most important cytokines involved in COVID-19 lesions, and known to be critical for the febrile response [9]. Indeed, it is known that IL-6 may cause hyponatremia by inducing the release of vasopressin. Prospective multicenter studies including urinary osmolality data, IL-6 measurement and the search for chronic underlying hyponatremia are needed in order to achieve a better understanding of SARS-CoV-2-induced hyponatremia.

In conclusion, our study showed a significant relationship between hyponatremia at admission and transfer to ICU, use of mechanical ventilation or death among 290
COVID-19 patients admitted to our hospital. Our results support considering sodium levels in hospitalized COVID19 patients as a tool for the early identification of patients at high risk of poor outcomes. Larger cohort and experimental studies are needed to clarify the physiopathology of hyponatremia in COVID-19 patients.

Acknowledgements We would like to thank all the clinicians involved in the care of the patients and who communicated their patient data.

Funding None.

Availability of data and material On request.

\section{Declarations}

Conflict of interest The authors declare that there is no conflict of interest in this work.

Ethics approval and consent to participate This retrospective study was approved by the local ethics committee (GNEDS).

Ethical statement The submitted work is original and has not been published elsewhere in any form or language (partially or in full). Results have been presented honestly without fabrication, falsification or inappropriate data manipulation.

\section{References}

1. The OpenSAFELY Collaborative, Williamson E, Walker AJ, Bhaskaran KJ, Bacon S, Bates C et al (2020) OpenSAFELY: factors associated with COVID-19-related hospital death in the linked electronic health records of 17 million adult NHS patients. Epidemiology. https://doi.org/10.1101/2020.05.06. 20092999

2. Cheng Y, Luo R, Wang K, Zhang M, Wang Z, Dong L et al (2020) Kidney disease is associated with in-hospital death of patients with COVID-19. Kidney Int. 69:752

3. Du R-H, Liang L-R, Yang C-Q, Wang W, Cao T-Z, Li M et al (2020) Predictors of mortality for patients with COVID-19 pneumonia caused by SARS-CoV-2: a prospective cohort study. Eur Respir J 55(5):2000524

4. Henry BM, de Oliveira MHS, Benoit S, Plebani M, Lippi G (2020) Hematologic, biochemical and immune biomarker abnormalities associated with severe illness and mortality in coronavirus disease 2019 (COVID-19): a meta-analysis. Clin Chem Lab Med. 58(7):1021-1028

5. Herold T, Jurinovic V, Arnreich C, Lipworth BJ, Hellmuth JC, von Bergwelt-Baildon $M$ et al (2020) Elevated levels of IL-6 and CRP predict the need for mechanical ventilation in COVID19. J Allergy Clin Immunol. 146:128-134.e4

6. Ruan Q, Yang K, Wang W, Jiang L, Song J (2020) Clinical predictors of mortality due to COVID-19 based on an analysis of data of 150 patients from Wuhan, China. Intensive Care Med. https://doi.org/10.1007/s00134-020-05991-x

7. Zhou F, Yu T, Du R, Fan G, Liu Y, Liu Z et al (2020) Clinical course and risk factors for mortality of adult inpatients with COVID-19 in Wuhan, China: a retrospective cohort study. Lancet Lond Engl. 395(10229):1054-1062 
8. Broman N, Rantasärkkä K, Feuth T, Valtonen M, Waris M, Hohenthal U et al (2020) IL-6 and other biomarkers as predictors of severity in COVID-19. Ann Med 11:1-5

9. Funk G-C, Lindner G, Druml W, Metnitz B, Schwarz C, Bauer P et al (2010) Incidence and prognosis of dysnatremias present on ICU admission. Intensive Care Med 36(2):304-311

10. Leong H-N, Earnest A, Lim H-H, Chin C-F, Tan CSH, Puhaindran ME et al (2006) SARS in Singapore-predictors of disease severity. Ann Acad Med Singapore 35(5):326-331

11. Leong H-N, Chan K-P, Oon LLE, Koay ESC, Ng L-C, Lee M-A et al (2006) Clinical and laboratory findings of SARS in Singapore. Ann Acad Med Singapore 35(5):332-339

12. Frontera JA, Valdes E, Huang J, Lewis A, Lord AS, Zhou T et al (2020) Prevalence and impact of hyponatremia in patients with coronavirus disease 2019 in New York City. Crit Care Med. https://doi.org/10.1097/CCM.0000000000004605

13. Hu W, Lv X, Li C, Xu Y, Qi Y, Zhang Z et al (2020) Disorders of sodium balance and its clinical implications in COVID-19 patients: a multicenter retrospective study. Intern Emerg Med. https://doi.org/10.1007/s11739-020-02515-9

14. Zeberg H, Pääbo S (2020) The major genetic risk factor for severe COVID-19 is inherited from Neanderthals. Nature 587(7835):610-612

15. Helms J, Kremer S, Merdji H, Clere-Jehl R, Schenck M, Kummerlen C et al (2020) Neurologic Features in Severe SARS-CoV-2 Infection. N Engl J Med. 382:2268-2270

16. Asadi-Pooya AA, Simani L (2020) Central nervous system manifestations of COVID-19: a systematic review. J Neurol Sci 413:116832

17. Müller M, Schefold JC, Guignard V, Exadaktylos AK, Pfortmueller CA (2018) Hyponatraemia is independently associated with in-hospital mortality in patients with pneumonia. Eur J Intern Med $54: 46-52$

18. Richardson S, Hirsch JS, Narasimhan M, Crawford JM, McGinn T, Davidson KW, et al (2020) Presenting Characteristics, Comorbidities, and Outcomes Among 5700 Patients Hospitalized With COVID-19 in the New York City Area. JAMA. https://jaman etwork.com/journals/jama/fullarticle/2765184. Accessed 23 Apr 2020

19. Tezcan ME, Dogan Gokce G, Sen N, Zorlutuna Kaymak N, Ozer RS (2020) Baseline electrolyte abnormalities would be related to poor prognosis in hospitalized coronavirus disease 2019 patients. New Microbes New Infect 37:100753

20. Li J, He X, Yuan Y, Zhang W, Li X, Zhang Y et al (2020) Metaanalysis investigating the relationship between clinical features, outcomes, and severity of severe acute respiratory syndrome coronavirus 2 (SARS-CoV-2) pneumonia. Am J Infect Control. 49:82-89

21. Yamada T, Wakabayashi M, Yamaji T, Chopra N, Mikami T, Miyashita $\mathrm{H}$ et al (2020) Value of leukocytosis and elevated C-reactive protein in predicting severe coronavirus 2019 (COVID19): A systematic review and meta-analysis. Clin Chim Acta Int J Clin Chem. 509:235-243

Publisher's Note Springer Nature remains neutral with regard to jurisdictional claims in published maps and institutional affiliations. 